OPEN ACCESS

Edited by:

Monica Pellerone

Kore University of Enna, Italy

Reviewed by:

Thelma Quince,

University of Cambridge,

United Kingdom

Tiziana Ramaci,

Kore University of Enna, Italy

*Correspondence:

Xu-Dong Zhao

zhaoxd62@gmail.com

Specialty section:

This article was submitted to

Educational Psychology,

a section of the journal

Frontiers in Psychology

Received: 09 April 2019 Accepted: 05 August 2019

Published: 21 August 2019

Citation:

Huang L, Thai J, Zhong Y, Peng H, Koran J and Zhao X-D (2019)

The Positive Association Between Empathy and Self-Esteem in Chinese Medical Students:

A Multi-Institutional Study.

Front. Psychol. 10:1921. doi: 10.3389/fpsyg.2019.01921

\section{The Positive Association Between Empathy and Self-Esteem in Chinese Medical Students: A Multi-Institutional Study}

\author{
Lei Huang ${ }^{1,2}$, Jessica Thai ${ }^{3}$, Yuan Zhong ${ }^{2}$, Hao Peng $^{4}$, Jessica Koran ${ }^{3}$ and \\ Xu-Dong Zhao ${ }^{4,5,6 *}$
}

'Department of Psychiatry, Tongji Hospital, Tongji University School of Medicine, Shanghai, China, ${ }^{2}$ Medical Education Division, Tongji Hospital, Tongji University School of Medicine, Shanghai, China, ${ }^{3}$ College of Medicine, University of Nebraska Medical Center, Omaha, NE, United States, ${ }^{4}$ School of Medicine, Tongji University, Shanghai, China, ${ }^{5}$ Shanghai East Hospital Affiliated to Tongji University, Shanghai, China, ${ }^{6}$ Shanghai Pudong New Area Mental Health Center, Tongji University School of Medicine, Shanghai, China

Background: Empathy is an important element of the physician-patient relationship and is a critical personality trait for medical students. However, research has shown that it declines during undergraduate medical education. It is still unclear how empathy interrelates with the psychological elements of medical students, in particular, selfesteem. This study examined the relationship between empathy and self-esteem to explore other possible methods to improve medical students' empathy.

Methods: A stratified sampling strategy was used to select 1690 medical students from 3 medical institutions in Shanghai as study participants. The questionnaires used to collect data included the Jefferson Scale of Physician Empathy-Student Version (JSPE-S), the Rosenberg Self-esteem Scale (RSES), and a self-made inventory on personal information. Descriptive analysis, independent $t$-test, One-Way ANOVA, and linear regression were used to analyze the data.

Results: The mean empathy score among medical students was 102.73 with $\mathrm{SD}=12.64$. Multiple regression analysis revealed that, "age," "perception of the importance of empathy," "academic pressure," "desire to be a doctor after graduation," and "self-esteem" were significant predictors of empathy $(P<0.05)$ and the adjusted $R^{2}$ was 0.462 . The correlation matrix between empathy and self-esteem was significant $(r=0.510, P<0.01)$. Self-esteem explained $15.5 \%$ of the variation of empathy in the final regression model.

Conclusion: There was a positive association between self-esteem and empathy. Self-esteem is one of many factors which contribute to medical students' empathy. Age, academic pressure, attitude toward empathy and future career also play a critical role in medical student empathy. Enhancing medical students' self-esteem may be an efficacious way to improve medical students' empathy.

Keywords: empathy, self-esteem, medical student, China, survey 


\section{INTRODUCTION}

Over the past 20 years, the patient-physician relationship has been deteriorating in China (Pan et al., 2015; He and Qian, 2016). Many complex reasons contribute to the tense relationship, but the lack of communication skills amongst physicians is an important factor (Blatt et al., 2009). Empathy is an essential component of communication skills and has increasingly become a crucial element for establishing positive patient-health provider relationships (Winefield and Chur-Hansen, 2000; Veloski et al., 2005; Loh and Sivalingam, 2008; Hojat et al., 2013). Studies have evidenced that empathic engagement in patient care leads to improved patient satisfaction and clinical outcomes (Kim et al., 2004; Hojat et al., 2011; Del Canale et al., 2012). Empathetic physicians experience greater job satisfaction, increased health and well-being, and improved clinical decision making (Kim et al., 2004; West et al., 2006; Hojat et al., 2015). Definitions of empathy are diverse. Hojat defines empathy as "a predominantly cognitive attribute that involves an understanding of experiences, concerns, and perspectives of the patient" (Hojat et al., 2002b). Morse considers empathy a construct composed of emotional, moral, cognitive and behavioral dimension (Morse et al., 1992). According to Hemmerdinger et al. (2007), empathy is a personality trait that enables one to identify with another's situation, thoughts, or condition by placing oneself in their situation. The commonality among these definitions is that empathy is part of a greater psychological domain. Empathy is a crucial element of effective physician-patient communication (Levinson, 1994; Winefield and Chur-Hansen, 2000). It is critical to study the characteristics of students with greater empathy and to encourage empathy development throughout medical training as studies have shown that empathy is considered a "positive personality attribute" (Hojat et al., 2015) and may better predict clinical competence than pre-admission test scores (Stratton et al., 2008).

Socio-demographic and academic factors including gender (Toussaint and Webb, 2005; Schulte-Ruther et al., 2008), year in school (Coulehan and Williams, 2001), and future career preference ( $\mathrm{Li}$ et al., 2018) affect medical student empathy. Psychological factors such as personality traits (Song and Shi, 2017; Abe et al., 2018), sense of power (Garden, 2009; Toto et al., 2015), stress, and burnout (Rosen et al., 2006; Gleichgerrcht and Decety, 2013; Yuguero Torres et al., 2015) are also influential factors. Several studies worldwide have also shown that women have higher empathy levels than men (Kataoka et al., 2009; Costa et al., 2013; Wen et al., 2013). There has also been evidence suggesting a decline in empathy in medical students in a number of countries as they progress through years of studies, although evidence was mixed (Coulehan and Williams, 2001). Some studies found a reduction (Colliver et al., 2010) in empathy levels during undergraduate education (Austin et al., 2007), while others found no change (Rahimi-Madiseh et al., 2010; Quince et al., 2011; Costa et al., 2013; Toto et al., 2015), or an increase (Kataoka et al., 2009; Magalhaes et al., 2011). Additionally, medical students who preferred not to become doctors had lower empathy than students who preferred to become doctors (Li et al., 2018). Physicians in "people oriented" specialties also consistently had higher empathy scores than those in "technology-oriented" specialties (Romero et al., 2016).

There is limited literature on empathy's role in medical students' greater psychological makeup. Although expressing empathy is linked to communication (Winefield and ChurHansen, 2000), it also involves a cognitive component with an intent to understand and comprehend others (Berg et al., 2011). In addition to empathy, another psycho-cognitive factor which benefits the patient-healthcare provider relationship is selfesteem (Öhlén and Segesten, 1998), which refers to how favorable an individual's opinion is of him/herself, positive and negative feelings toward oneself, and his/her personal values (Alkhateeb, 2014). Self-esteem has been strongly correlated with personality traits, affectivity, and extraversion (Watson et al., 2002) as well as self-efficacy (Lane et al., 2004). Individuals with high selfesteem are more capable of handling stress, reducing anxiety and burnout, and developing better communication skills and interpersonal relationships (Kirkpatrick and Ellis, 2006; Edwards et al., 2010). Improved coping mechanisms and increased selfefficacy may mediate a positive relationship between self-esteem and academic performance (Lent et al., 1986; Magnano et al., 2014). While self-esteem and empathy are both influential psychological factors in medical student performance, there have been few studies on the relationship between self-esteem and empathy in medical students. One study by Liu showed a negative relationship between empathy and self-esteem in Chinese medical students (Hanlong, 2012). Other studies on Chinese nursing students and college students had reversed results and suggested that self-esteem was a positive predictor of empathy (Hui, 2002; Hongrui et al., 2016). Another study found that healthcare professionals with higher self-esteem and empathy levels had lower burnout rates (Molero Jurado et al., 2018).

This research study hypothesizes that self-esteem influences medical student empathy. Improving medical students' selfesteem or discovering mediating factors between self-esteem and empathy may enhance medical students' empathy. To our knowledge, the correlation between empathy and self-esteem in medical students has not been fully interpreted. Inconsistent past study results may have occurred from study participants spanning across different specialties and from a limited sample size. This research study consequently examines the relationship between self-esteem and empathy in medical students in China, in addition to assessing the differences in empathy scores by gender, year of study, and other academic factors via a multiinstitutional design.

\section{MATERIALS AND METHODS}

\section{Participants}

A total of 1958 medical students were invited to this study and 1690 chose to participate. The response rate was $86.31 \%$. 693(41.01\%) students were from Fudan University Shanghai Medical College, 576(34.08\%) students were from Shanghai Jiao Tong University School of Medicine, and 421(24.91\%) students were from Tongji University School of Medicine. This study used a stratified sampling strategy to select randomly 
select subjects by inviting 120-150 students to participate from each medical student year from each of the three universities. The sample consisted of 707(41.83\%) male and 983 (58.17\%) female participants. Participant age ranged from 16-27 years $(\mathrm{M}=20.26, \mathrm{SD}=1.622)$. All participants attended medical school in Shanghai, were unmarried, high school graduates, and most were from single-child families. According to the medical undergraduate education system among the three institutions, medical students were divided into three stages by school year. $785(46.45 \%)$ students were in basic medical science courses from first to second year, 603(35.68\%) students were in clinical courses from third to fourth year, and $302(17.87 \%)$ students were in internships in their fifth year.

\section{Measures \\ Jefferson Scale of Physician Empathy-Student Version (JSPE-S)}

Empathy was measured via the Jefferson Scale of Physician Empathy-Student Version (JSPE-S) (Hojat et al., 2018), which is a validated instrument for use with medical students. The JSPE-S itself is a 20 -item questionnaire, 10 items of which are negatively worded and reverse scored and is delivered using a 7-point Likert scale. It is widely used and has been translated in 54 languages, including Chinese (Wen et al., 2013). Students were provided with a statement to which they chose an option between strongly disagree and strongly agree. Possible scores ranged from 20 to 140 , with higher scores indicating possibly higher empathy levels (Hojat et al., 2002; Hojat et al., 2003; Sherman and Cramer, 2005). In this study, the Cronbach's alpha coefficient was 0.838 .

\section{Rosenberg Self-Esteem Scale (RSES)}

This study evaluated self-esteem with the RSES (Rosenberg, 1965), which is a self-rating scale consisting of 10 items, using a 4point Likert scale to rate, with options ranging from " 1 = strongly disagree" to " $4=$ strongly agree." The total score ranged from 10 points to 40 points. Higher scores indicated higher self-esteem. The scale was shown to have good reliability and validity in regards to Chinese culture (Zhao et al., 2012; Kong and You, 2013). In this current study, the Cronbach's alpha coefficient of RSES was 0.857 .

\section{Self-Reported Personal Information}

Personal information was collected, including (1) sociodemographic factors: "gender" with the binary answer " $1=$ male" and " 2 = female," age; (2) academic factors: "year of school" with the answer " 1 = Basic science course (the 1st and 2 nd year)," " 2 = Clinical course (the 3 rd and 4 th year)," " 3 = Internship (the 5 th year)"; "academic pressure" assessed with multiple categorical answer "1 = low," "2 = moderate," " 3 = Important"; "perception of the importance of empathy" assessed with multiple categorical answer " 1 = not important," " 2 = ambivalent," "3 = important"; "desire to be a doctor after graduation" with the binary answer " $0=$ no" and " 1 = yes".

\section{Procedure}

Participants were instructed to complete a questionnaire survey including measures of empathy, self-esteem and personal information in the classroom after signing informed consent forms. Three staff from Fudan University Shanghai Medical College, Shanghai Jiao Tong University School of Medicine, and Tongji University School of Medicine administered the survey. It took approximately $15 \mathrm{~min}$ for students to complete all the instruments. Each participant received a pen for participating in the study.

\section{Data Analysis}

The Statistical Package for Social Sciences (SPSS; Version 19.0) was used for data storage, tabulation, and the generation of descriptive statistics. Statistical means were used to describe the descriptive data. Independent samples $t$-test and OneWay Analysis of Variance (ANOVA) were used to compare empathy levels among. Groups were divided via self-reported data including gender, year of school, academic pressure, perception of the importance of empathy, and desire to become a doctor after graduation. Pearson correlation and multivariate stepwise regression were conducted to explore how levels of empathy and self-esteem as well as other personal factors were related. All tests were two tailed unless otherwise stated. Results were considered statistically significant if the $p$ value was $<0.05$.

\section{RESULTS}

\section{Descriptive Analysis of Empathy and Self-Esteem}

As shown in Table 1, mean empathy level was $\mathrm{M}_{\text {empathy }}=102.73$, $\mathrm{SD}_{\text {empathy }}=12.64$. With regard to the three subscales, mean “perspective taking" score was $\mathrm{M}_{P T}=54.75, \mathrm{SD}_{P T}=7.78$, mean “compassionate care" score was $\mathrm{M}_{c c}=39.78, \mathrm{SD}_{c c}=6.05$, and mean "standing in patient shoes" scores was $\mathrm{M}_{S I S S}=8.20$, $\mathrm{SD}_{\text {SISS }}=2.46$. Mean self-esteem assessed by RSES score ranged was $\mathrm{M}_{S E}=31.23, \mathrm{SD}_{S E}=4.08$.

\section{Correlation Between Empathy and Self-Esteem as Well as Personal Variables}

Independent samples $t$-test and One-Way ANOVA showed significant correlations among empathy and all of the personal variables defined in this study, including "gender" $(t=-2.908$, $p=0.004)$, "year of school" $(F=11.467, p<0.001)$, "perception of the importance of empathy" ( $F=168.321, p<0.001)$, "academic pressure" ( $F=7.685, p<0.001)$, and "desire to be a doctor after

TABLE 1 | Descriptive analysis of JSPE-S and RSES ( $n=1690)$.

\begin{tabular}{lrccc}
\hline Variables & Mean & SD & Min & Max \\
\hline JSPE-S & 102.73 & 12.64 & 60 & 140 \\
Perspective taking & 54.75 & 7.78 & 31 & 70 \\
Compassionate care & 39.78 & 6.05 & 12 & 56 \\
Standing in the patient's shoes & 8.20 & 2.46 & 2 & 14 \\
RSES & 31.23 & 4.08 & 18 & 40
\end{tabular}


TABLE 2 | Comparison of the level of empathy among groups with different personal and academic variables.

\begin{tabular}{|c|c|c|c|c|c|c|c|}
\hline Variables & $n$ & $\%$ & JSPE-S Mean & JSPE-S SD & $\mathbf{t} / \mathbf{F}$ & & $p$ \\
\hline \multicolumn{8}{|l|}{ Gender } \\
\hline Male & 707 & 41.83 & 101.68 & 13.19 & -2.908 & & 0.004 \\
\hline Female & 983 & 58.17 & 103.49 & 12.17 & & & \\
\hline \multicolumn{8}{|l|}{ Year of school } \\
\hline Basic science course (1st and 2nd) & 785 & 46.45 & 103.92 & 12.85 & 11.467 & $p$ & $<0.001$ \\
\hline Clinical course (3rd and 4th) & 603 & 35.68 & 102.64 & 12.31 & & & \\
\hline Internship (5th) & 302 & 17.87 & 99.85 & 12.29 & & & \\
\hline \multicolumn{8}{|l|}{ Academic pressure } \\
\hline Low & 67 & 4.00 & 97.40 & 13.99 & 7.685 & $p$ & $<0.001$ \\
\hline Moderate & 861 & 50.90 & 102.46 & 12.76 & & & \\
\hline High & 762 & 45.10 & 103.52 & 12.25 & & & \\
\hline \multicolumn{8}{|c|}{ Perception of the importance of empathy } \\
\hline Not important & 49 & 2.90 & 82.24 & 8.36 & 168.321 & $p$ & $<0.001$ \\
\hline Ambivalent & 163 & 9.54 & 91.91 & 9.19 & & & \\
\hline Important & 1478 & 87.46 & 104.61 & 11.86 & & & \\
\hline \multicolumn{8}{|l|}{ Desire to be a doctor after graduation } \\
\hline Yes & 1588 & 94.00 & 103.11 & 12.54 & 4.891 & $p$ & $<0.001$ \\
\hline No & 102 & 6.00 & 96.84 & 12.76 & & & \\
\hline
\end{tabular}

TABLE 3 | Correlation analysis between empathy and self-esteem.

\begin{tabular}{lcccc}
\hline Variables & $\begin{array}{c}\text { Perspective } \\
\text { taking }\end{array}$ & $\begin{array}{c}\text { Compassionate } \\
\text { care }\end{array}$ & $\begin{array}{c}\text { Standing in } \\
\text { the patient's } \\
\text { shoes }\end{array}$ & JSPE-S \\
\hline Age & $-0.116^{* *}$ & $-0.093^{* *}$ & $-0.068^{* *}$ & $-0.130^{* *}$ \\
RSES & $0.430^{* *}$ & $0.418^{* *}$ & $0.230^{* *}$ & $0.510^{* *}$ \\
\hline$* * p<0.01$. & & & & \\
\hline
\end{tabular}

graduation" ( $t=4.891, p<0.001)$ (Table 2$)$. The correlation matrix between empathy and age $(r=-0.130, p<0.01)$ as well as self-esteem $(r=0.510, p<0.01)$ were statistically significant (Table 3).

\section{Multivariate Regression Analysis}

To investigate the relationship between students' empathy and a single factor with marked discrepancy, we took the sum of JSPE-S scores as the dependent variable, and "gender," "age," "year of school," "academic pressure," "perception of the importance of empathy," "desire to be a doctor after graduation," and "self-esteem" as the independent variables. A linear regression and the stepwise method were used to determine the main factors (Stepwise Criteria: Probability-ofF-to-enter $\leq 0.050$, Probability-of-F-to-remove $\geq 0.100)$. Of the three models, the third had the highest $R^{2}$ value $(0.468)$ and was consequently selected as the final model. Furthermore, we found that "age," "perception of the importance of empathy," "academic pressure," "desire to be a doctor after graduation," and "self-esteem" were significantly predictors of empathy $(p<0.05)$. Moreover, "age" showed justified negative correlations with empathy, while the others showed positive correlations (Tables 4, 5).

\section{DISCUSSION}

Empathy has been considered the royal road to an optimal physician-patient relationship and overall physician competence in China (Blatt et al., 2009). In this study, the mean score for medical students in Shanghai $(M=102.73)$ was similar to previous studies on medical students of one institution in Shanghai ( $\mathrm{M}=104.2)$ ( $\mathrm{Li}$ et al., 2018). However, scores were slightly lower than a study by Wen from Liaoning province $(M=109.60)$ (Wen et al., 2013). This may be explained by the study participants' differences in academic year. In Wen's study, participants were in their first to fourth years in medical school, and the study excluded internship medical students, which may have influenced mean empathy scores. Nonetheless, the overall empathy level of Chinese medical students was significantly lower than that of American medical students (Hojat et al., 2002a). This may be due to cultural differences. It has been suggested that factors such as decreased physician to patient ratios or an overabundance of patients may result in increased burnout and decrease empathy (Diez-Goni and Rodriguez-Diez, 2017). With China's immense patient population, Chinese medical students may feel overwhelmed and forced to rush through clinical diagnoses and patient visits, leading to distress and lower empathy levels. Furthermore, the increasing use of technology in medicine in China may dehumanize health care providers from empathizing with patients ( $\mathrm{Li}$ et al., 2018). At the same time, with the wide range of Chinese socioeconomic classes (Bian et al., 2005), Chinese medical students may feel superior to some of their patients, leading to mechanized, emotionally detached medicine (Li et al., 2018). This is concerning because the developmental course of empathy in Chinese medical students across their careers is poorly understood. There may be a possible decrement in empathy across Chinese medical education. A more sophisticated understanding of empathy in medical students is 
TABLE 4 | Stepwise model summary between empathy and the single factor with marked discrepancy.

\begin{tabular}{|c|c|c|c|c|c|c|c|c|c|}
\hline \multirow[t]{2}{*}{ Model } & \multirow[t]{2}{*}{$\boldsymbol{R}$} & \multirow[t]{2}{*}{$R^{2}$} & \multirow[t]{2}{*}{ Adjusted $R^{2}$} & \multirow[t]{2}{*}{ Standard error of the estimate } & \multicolumn{5}{|c|}{ Change statistics } \\
\hline & & & & & $R$ change & $F$ change & df1 & df2 & $p$ change \\
\hline$(1)$ & $0.148^{a}$ & 0.022 & 0.021 & 12.504 & 0.022 & 18.976 & 2 & 1687 & 0.000 \\
\hline (2) & $0.556^{b}$ & 0.309 & 0.307 & 10.523 & 0.287 & 174.732 & 4 & 1683 & 0.000 \\
\hline (3) & $0.681^{c}$ & 0.464 & 0.462 & 9.271 & 0.155 & 486.182 & 1 & 1682 & 0.000 \\
\hline
\end{tabular}

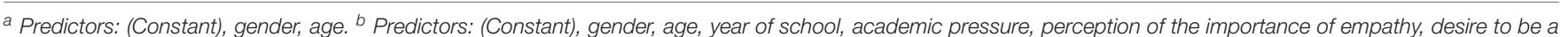

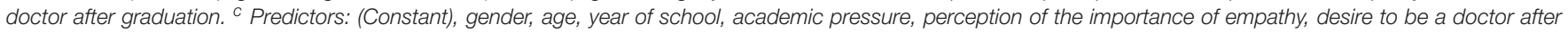
graduation, self-esteem.

needed, with attention to issues that may adversely impact this crucial aspect of their development (Mahoney et al., 2016).

"Self-esteem" was the second most important predictor of empathy in our study, which was consistent with a study on Chinese nursing students (Hongrui et al., 2016) and college students (Hui, 2002) which revealed that participants with higher RSES scores received higher JSPE-S scores. However, this study contradicted Liu's study on Chinese medical students (Hanlong, 2012), which showed that self-esteem was negatively correlated with medical students' empathy. In Liu's study, individuals with higher self-esteem tended to identify with individuals with their own values and could not accept others' opinions and feelings. Research has indicated that empathy has been linked, theoretically and empirically, to several psychological attributes, such as personality, stress, anxiety, and burnout. Similarly, self-esteem may affect empathy by these same attributes as self-esteem is correlated with personality and one's value system (Iacobucci et al., 2013). Previous studies have shown that self-esteem was strongly negatively correlated with neuroticism/negative affectivity and moderately to strongly related to extraversion/positive affectivity (Watson et al., 2002). Individuals with high self-esteem may be more positive and optimistic and have a good sense of security, self-control, and motivation. These feelings and personality traits may consequently help stress management and reduce anxiety or dissatisfaction with life (Xiangkui and Lumei, 2005; Fangsong, 2006). Healthier mentality and positive emotion may also improve the development of better interpersonal relationships (Kirkpatrick and Ellis, 2006), while low selfesteem may lead to emotional problems such as anxiety and sociophobia, which negatively influence interpersonal relationships (Edwards et al., 2010).

Furthermore, stress and anxiety have been shown to lead to occupational burnout (Cass et al., 2016; Youssef, 2016; Zhou et al., 2016; Patel et al., 2017), which may significantly reduce medical students' empathy (Thomas et al., 2007; Gleichgerrcht and Decety, 2013; Yuguero Torres et al., 2015). According to Alvaro's conservation of resources theory, accumulating condition resources such as increased well-being and lower rates of burnout may allow greater access to other personal resources. Self-esteem was defined as one of these personal resources which alleviated burnout (Alvaro et al., 2010). Additionally, initial levels of empathy for patients may lead to increased patient satisfaction and positive feedback from patients. This may create a self-perpetuating positive reinforcement cycle, which continues to increase health care providers' empathy levels (Pollak et al., 2011). In addition to higher patient satisfaction, an additional explanation for positive reinforcement of patient empathy levels is the association between empathy, higher communication, and interpersonal skills, which allow physicians to easily express empathy, create better physicianpatient relationships, and receive positive reinforcement to continue expressing empathy (Winefield and Chur-Hansen, 2000; Pollak et al., 2011). It has been suggested that self-esteem is linked with skilled communication (Carson et al., 2001). Individuals with better communication skills and higher selfesteem may be more adept at expressing empathy, leading to greater patient satisfaction and subsequently, an increased desire to continue expressing empathy in the future. This suggests that medical students with greater communication and interpersonal relationship training may be more comfortable expressing empathy (Winefield and Chur-Hansen, 2000; Pollak et al., 2011).

In the final model of regression, "perception of the importance of empathy" was the most significant predictor of empathy. "Academic pressure" as well as "desire to be a doctor after graduation" were also positive but weak contributors of medical students' empathy. These results suggest that medical students who had a positive attitude toward empathy and future career had higher empathy scores, which echoes a study by Li et al. (2018) which found that medical students who did not want to become physicians had lower empathy scores than medical students who were still unsure of their passion to become physicians. This may be explained by differences in Chinese vs. American medical education. Chinese medical students choose their specialty after senior middle school graduation. Some students do not choose medicine as their career voluntarily, and they may have little interest in medicine and low motivation to become a doctor after their studies (Wang et al., 2014). In contrast, American students must finish their relative undergraduate degree (biology, etc.) before entering medical school and may pursue medicine as a future career with more mature, intentional thought. Additionally, only students with distinct, desirable personality traits such as high empathy may garner acceptance into such competitive American medical schools (Lumsden et al., 2005). Furthermore, medical school curriculum is quite different between China and the United States. While empathy has been recognized as an important ability for medical students, it is still not integrated into most Chinese medical school curriculum 


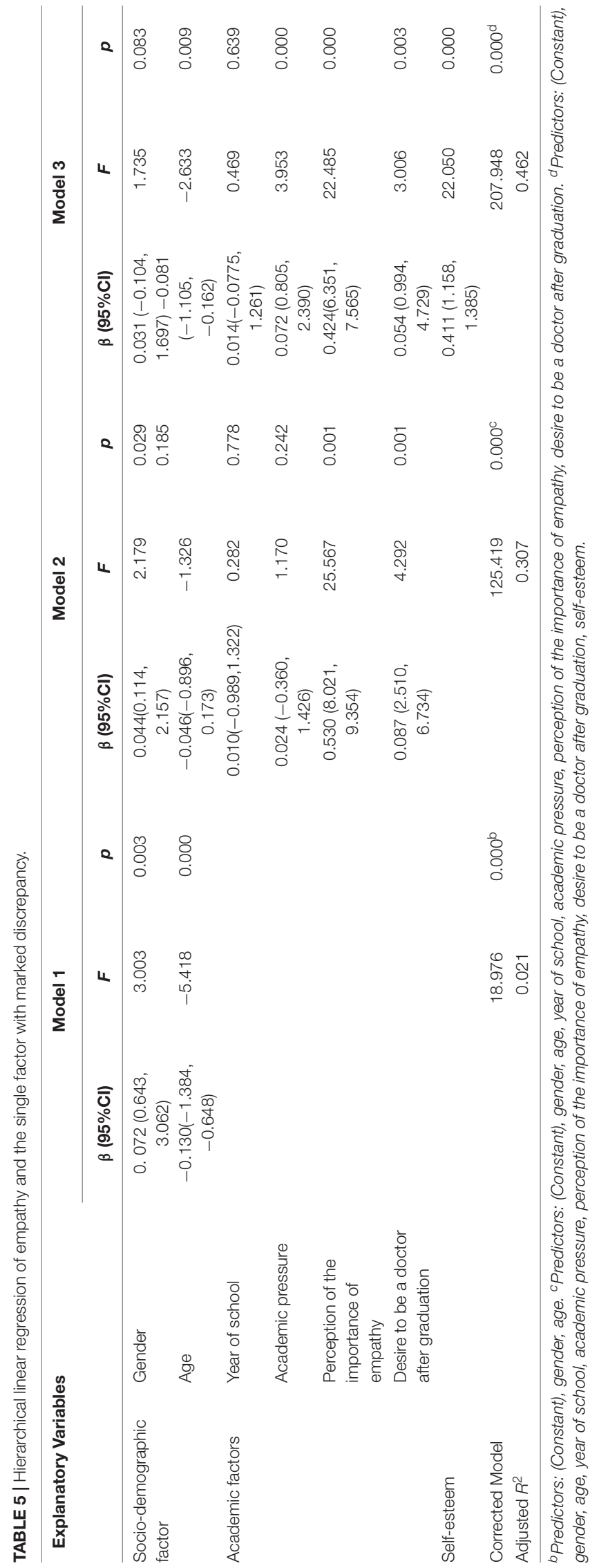

(Wen et al., 2013). On the other hand, empathy is objectively assessed on the United States USMLE, which may increase medical students' emphasis on empathy (Hojat et al., 2002a) and may pressure students to be more empathetic.

Bivariate analysis showed that empathy scores of participants decreased with increasing years of medical training and were lowest during the final clerkship year. Female medical students had greater empathy scores than male participants. However, after controlling for gender and age in the regression analysis, gender and "year of school" did not significantly affect empathy. This hinted that the significant effects seen in the bivariate analysis may be because of other factors which were not controlled for in the multivariate analyses. Although the associations between gender and "year of school" were insignificant after adjusting for some covariates, previous studies illustrated that factors such as gender and "year of school" may affect empathy (Coulehan and Williams, 2001). Therefore, future investigations should include surveys with larger sample sizes and more detailed participant information.

Age was a weak negative predictor of empathy in this study which may be because younger age is associated with increased empathy from less burnout and fatigue in the medical profession (DiLalla et al., 2004). Another explanation may be that older age is correlated with years of clinical training in medical school. United States medical students often take gap years between undergraduate education and medical school and maybe of various ages at medical school admission. On the other hand, it is common in China to matriculate into medical school immediately after high school. As such, Chinese first year medical students are typically younger than second and third year medical students (Chen et al., 2010). As older students gain clinical experience in medical school, they may emotionally harden to being exposed to pain, death, and hardships to mentally protect themselves (Coulehan and Williams, 2001). Likewise, even in the United States, where medical student age may not correlate as well with years of clinical training as in China, older individuals may have accumulated more life experience regarding suffering and may become jaded more easily than younger individuals (Eysenck et al., 1985).

Empathy education is a vital part of medical students' empathy development. Chinese medical students' low empathy in this study suggests that current education patterns need improvement. Furthermore, our research found a positive relationship between self-esteem and empathy, as well as academic attitude and empathy. These results suggest that factors decreasing self-esteem or mediating factors such as personality, stress or burnout may subsequently negatively affect empathy levels. Improving medical students' professional identity as well as increasing educational emphasis on empathy may help increase medical students' self-esteem and empathy.

\section{Strengths and Limitations}

To our knowledge, this is the first multi-institutional study on Chinese medical students' self-esteem and empathy. However, we also acknowledge that participants were medical students solely from Shanghai, who were unmarried, mainly from singlechild families, and ranged from ages 16-27. This sample 
is not necessarily representative of empathy levels among medical undergraduates nationwide. Furthermore, participants responded via self-report questionnaires. While these instruments have been validated for the Chinese population, the use of self-reported assessments and the retrospective study design may decrease data validity. Additionally, as this study is cross-sectional and descriptive, future research should confirm our findings via a longitudinal and prospective study. Finally, although the relationship between self-esteem and empathy was positively correlated in this study, there is still a need for further investigation of possible mediating factors such as stress, anxiety, burnout, or wellness.

\section{CONCLUSION}

Empathy is a particularly important disposition for medical students and toward their future careers as doctors. Selfesteem is one of many influential factors toward medical students' empathy. This study revealed that there is a positive association between self-esteem and empathy. School year, academic pressure, attitude toward empathy, and desire to be a doctor after graduation are also positively correlated with empathy level while age is indirectly related to empathy. By increasing self-esteem and empathy in medical students and physicians, the quality of the patient-physician relationship may be improved, resulting in reciprocally beneficial outcomes. Patients may become more trusting of physicians and be more open to disclosing their concerns to empathetic physicians. Likewise, empathetic, high self-esteem physicians may be more adept at handling sensitive, emotional patient situations. As such, improving self-esteem and empathy in medical students and physicians is a critical component of providing quality health care. Further research may explore additional mediating factors between self-esteem and empathy. Future studies may also investigate the relationship between self-esteem and empathy in medical students outside of Shanghai such as in more rural cities or in different regions of China. This study may also be replicated outside of China to investigate if there is a cultural influence on self-esteem and empathy.

\section{DATA AVAILABILITY}

All datasets generated for this study are included in the manuscript and/ro the Supplementary Files.

\section{REFERENCES}

Abe, K., Niwa, M., Fujisaki, K., and Suzuki, Y. (2018). Associations between emotional intelligence, empathy and personality in Japanese medical students. BMC Med. Educ. 18:47. doi: 10.1186/s12909-018-1165-7

Alkhateeb, H. M. (2014). Self-esteem is characterized as a positive or a negative attitude toward the self (Rosenberg, 1965, cited in Mruk, 2006)." [corrected]. Psychol. Rep. 114, 971-973. doi: 10.2466/11.07.PR0.114 k28w1

Alvaro, C., Lyons, R. F., Warner, G., Hobfoll, S. E., Martens, P. J., Labonte, R., et al. (2010). Conservation of resources theory and research use in health systems. Implement. Sci. 5:79. doi: 10.1186/1748-5908-5-79

\section{ETHICS STATEMENT}

Our study had an ethics approval from the School of Medicine Ethics Committee, Tongji University School of Medicine, Shanghai, China and we acquired written informed consent from study participants.

\section{AUTHOR CONTRIBUTIONS}

LH contributed to study design, recruitment of participants, data analysis and interpretation and writing of the manuscript. JT and $\mathrm{JK}$ assisted in the interpretation of the results and draft writing. $\mathrm{YZ}$ and $\mathrm{HP}$ assisted in the data acquisition and recruitment of participants. X-DZ contributed to study design and supervision. All authors have approved the final manuscript.

\section{FUNDING}

The Outstanding Clinical Discipline Project of Shanghai Pudong (PWYgy2018-10) and Priority of Shanghai key discipline of medicine (2017ZZ02020).

\section{ACKNOWLEDGMENTS}

The authors gratefully acknowledge the study participants from Fudan University Shanghai Medical College, Shanghai Jiao Tong University School of Medicine, and Tongji University School of Medicine. All research participants were college students and their informed consent to participate was obtained by virtue of survey completion after they were provided with sufficient information about the study. If they were under 18 years of age, this was obtained through their parents.

\section{SUPPLEMENTARY MATERIAL}

The Supplementary Material for this article can be found online at: https://www.frontiersin.org/articles/10.3389/fpsyg. 2019.01921/full\#supplementary-material

DATA SHEET S1 | The Positive Association between Empathy and Self-esteem in Chinese Medical Students.

Austin, E. J., Evans, P., Magnus, B., and O’Hanlon, K. (2007). A preliminary study of empathy, emotional intelligence and examination performance in $\mathrm{MBChB}$ students. Med. Educ. 41, 684-689. doi: 10.1111/j.1365-2923.2007.02795.x

Berg, K., Majdan, J. F., Berg, D., Veloski, J., and Hojat, M. (2011). A comparison of medical students' self-reported empathy with simulated patients' assessments of the students' empathy. Med. Teach. 33, 388-391. doi: 10.3109/0142159x.2010. 530319

Bian, Y., Breiger, R., Galaskiewicz, J., and Davis, D. (2005). Occupation, class, and social networks in Urban China. Soc. Forces 83, 1143-1167. doi: 10.1353/sof. 2005.0053

Blatt, B., Kallenberg, G., Lang, F., Mahoney, P., Patterson, J., Dugan, B., et al. (2009). Found in translation: exporting patient-centered communication and 
small group teaching skills to China. Med. Educ. Online 14, 6. doi: 10.3885/meo. 2009.T0000136

Carson, J., Harman, K., and Webb, S. (2001). Assessing and measuring self-esteem in mental health: a comparison of scales in current use. Ment. Health Care 41, 336-339.

Cass, I., Duska, L. R., Blank, S. V., Cheng, G., duPont, N. C., Frederick, P. J., et al. (2016). Stress and burnout among gynecologic oncologists: a society of gynecologic oncology evidence-based review and recommendations. Gynecol. Oncol. 143, 421-427. doi: 10.1016/j.ygyno.2016.08.319

Chen, D. C., Pahilan, M. E., and Orlander, J. D. (2010). Comparing a selfadministered measure of empathy with observed behavior among medical students. J. Gen. Intern. Med. 25, 200-202. doi: 10.1007/s11606-009-1193-4

Colliver, J. A., Conlee, M. J., Verhulst, S. J., and Dorsey, J. K. (2010). Reports of the decline of empathy during medical education are greatly exaggerated: a reexamination of the research. Acad. Med. 85, 588-593. doi: 10.1097/ACM. 0b013e3181d281dc

Costa, P., Magalhaes, E., and Costa, M. J. (2013). A latent growth model suggests that empathy of medical students does not decline over time. Adv. Health Sci. Educ. Theory Pract. 18, 509-522. doi: 10.1007/s10459-012-9390-z

Coulehan, J., and Williams, P. C. (2001). Vanquishing virtue: the impact of medical education. Acad. Med. 76, 598-605. doi: 10.1097/00001888-200106000-00008

Del Canale, S., Louis, D. Z., Maio, V., Wang, X., Rossi, G., Hojat, M., et al. (2012). The relationship between physician empathy and disease complications: an empirical study of primary care physicians and their diabetic patients in Parma. Italy. Acad. Med. 87, 1243-1249. doi: 10.1097/ACM.0b013e3182628fbf

Diez-Goni, N., and Rodriguez-Diez, M. C. (2017). Why teaching empathy is important for the medical degree. Rev. Clin. Esp. 217, 332-335. doi: 10.1016/ j.rce.2017.01.005

DiLalla, L. F., Hull, S. K., and Dorsey, J. K. (2004). Effect of gender, age, and relevant course work on attitudes toward empathy, patient spirituality, and physician wellness. Teach. Learn. Med. 16, 165-170. doi: 10.1207/s15328015tlm1602_8

Edwards, D., Burnard, P., Bennett, K., and Hebden, U. (2010). A longitudinal study of stress and self-esteem in student nurses. Nurse Educ. Today 30, 78-84. doi: 10.1016/j.nedt.2009.06.008

Eysenck, S. B. G., Pearson, P. R., Easting, G., and Allsopp, J. F. (1985). Age norms for impulsiveness, venturesomeness and empathy in adults. Pers. Individ. Diff. 6, 613-619. doi: 10.1016/0191-8869(85)90011-X

Fangsong, W. (2006). The realization of doctor-patient communication. Jiangsu Health Care Manag. 17, 11-15.

Garden, R. (2009). Expanding clinical empathy: an activist perspective. J. Gen. Intern. Med. 24, 122-125. doi: 10.1007/s11606-008-0849-9

Gleichgerrcht, E., and Decety, J. (2013). Empathy in clinical practice: how individual dispositions, gender, and experience moderate empathic concern, burnout, and emotional distress in physicians. PLoS One 8:e61526. doi: 10.1371/ journal.pone.0061526

Hanlong, L. (2012). The Characteristics of Medical Students' Empathy and Relevant Factors. Tianjin: Tianjin Medical University.

He, A. J., and Qian, J. (2016). Explaining medical disputes in Chinese public hospitals: the doctor-patient relationship and its implications for health policy reforms. Health Econ. Policy Law 11, 359-378. doi: 10.1017/ S1744133116000128

Hemmerdinger, J. M., Stoddart, S. D., and Lilford, R. J. (2007). A systematic review of tests of empathy in medicine. BMC Med. Educ. 7:24. doi: 10.1186/1472-69207-24

Hojat, M., DeSantis, J., Shannon, S. C., Mortensen, L. H., Speicher, M. R., Bragan, L., et al. (2018). The Jefferson scale of empathy: a nationwide study of measurement properties, underlying components, latent variable structure, and national norms in medical students. Adv. Health Sci. Educ. Theory Pract. 23, 899-920. doi: 10.1007/s10459-018-9839-9

Hojat, M., Gonella, J. S., Mangione, S. J., Nasca, T. J., Veloski, J. J., et al. (2002). Empathy in medical students as related to academic performance, clinical competence and gender. Med. Educ. 36, 522-527. doi: 10.1046/j.1365-2923. 2002.01234.x

Hojat, M., Gonnella, J. S., Mangione, S., Nasca, T. J., Veloski, J. J., Erdmann, J. B., et al. (2002a). Empathy in medical students as related to academic performance, clinical competence and gender. Med. Educ. 36, 522-527. doi: 10.1046/j.13652923.2002.01234.x
Hojat, M., Gonnella, J. S., Nasca, T. J., Mangione, S., Vergare, M., and Magee, M. (2002b). Physician empathy: definition, components, measurement, and relationship to gender and specialty. Am. J. Psychiatry 159, 1563-1569. doi: 10.1176/appi.ajp.159.9.1563

Hojat, M., Gonnella, J. S., Nasca, T. J., Fields, S. K., Cicchetti, A., Scalzo, A. L., et al. (2003). Comparisons of American, Israeli, Italian and Mexican physicians and nurses on the total and factor scores of the Jefferson scale of attitudes toward physician-nurse collaborative relationships. Int. J. Nurs. Stud. 40, 427-435. doi: 10.1016/s0020-7489(02)00108-6

Hojat, M., Louis, D. Z., Maio, V., and Gonnella, J. S. (2013). Empathy and health care quality. Am. J. Med. Qual. 28, 6-7. doi: 10.1177/1062860612464731

Hojat, M., Louis, D. Z., Markham, F. W., Wender, R., Rabinowitz, C., and Gonnella, J. S. (2011). Physicians' empathy and clinical outcomes for diabetic patients. Acad. Med. 86, 359-364. doi: 10.1097/ACM.0b013e3182086fe1

Hojat, M., Vergare, M., Isenberg, G., Cohen, M., and Spandorfer, J. (2015). Underlying construct of empathy, optimism, and burnout in medical students. Int. J. Med. Educ. 6, 12-16. doi: 10.5116/ijme.54c3.60cd

Hongrui, Z., Hui, Z., Xiaofan, L., Fenghua, L., and Shuyao, J. (2016). The current status and correlation of empathy ability and self-esteem level among nursing students. Nurs. J. Chin. People's Liberat. Army 33, 1-4.

Hui, J. (2002). Research on the Mechanism of Empathy in Moral Behavior and Value of Moral Education. Nanjing: Nanjing Normal University.

Iacobucci, T. A., Daly, B. J., Lindell, D., and Griffin, M. Q. (2013). Professional values, self-esteem, and ethical confidence of baccalaureate nursing students. Nurs. Ethics 20, 479-490. doi: 10.1177/0969733012458608

Kataoka, H. U., Koide, N., Ochi, K., Hojat, M., and Gonnella, J. S. (2009). Measurement of empathy among Japanese medical students: psychometrics and score differences by gender and level of medical education. Acad. Med. 84, 1192-1197. doi: 10.1097/ACM.0b013e3181b180d4

Kim, S. S., Kaplowitz, S., and Johnston, M. V. (2004). The effects of physician empathy on patient satisfaction and compliance. Eval. Health Prof. 27, 237-251. doi: $10.1177 / 0163278704267037$

Kirkpatrick, L. A., and Ellis, B. J. (2006). "What is the evolutionary significance of self-esteem? the adaptive functions of self-evaluative psychological mechanisms," in Self-Esteem Issues and Answers: A Sourcebook of Current Perspectives, ed. M. H. Kernis (New York, NY: Psychology Press), 334-339.

Kong, F., and You, X. (2013). Loneliness and self-esteem as mediators between social support and life satisfaction in late adolescence. Soc. Indic. Res. 110, 271-279. doi: 10.1007/s11205-011-9930-6

Lane, J., Lane, A., and Kyprianou, A. (2004). Self-efficacy, self-esteem and their impact on academic performance. Soc. Behav. Pers. 32, 247-256. doi: 10.2224/ sbp.2004.32.3.247

Lent, R. W., Brown, S. D., and Larkin, K. C. (1986). Self-efficacy in the prediction of academic performance and perceived career options. J. Couns. Psychol. 33, 265-269. doi: 10.1037/0022-0167.33.3.265

Levinson, W. (1994). Physician-patient communication. A key to malpractice prevention. JAMA 272, 1619-1620. doi: 10.1001/jama.272.20.1619

Li, D., Xu, H., Kang, M., and Ma, S. (2018). Empathy in Chinese eight-year medical program students: differences by school year, educational stage, and future career preference. BMC Med. Educ. 18:241. doi: 10.1186/s12909-0181348-2

Loh, K. Y., and Sivalingam, N. (2008). Enhancing doctor-patient relationship: the humanistic approach. Med. J. Malaysia 63, 85-87; quiz88.

Lumsden, M. A., Bore, M., Millar, K., Jack, R., and Powis, D. (2005). Assessment of personal qualities in relation to admission to medical school. Med. Educ. 39, 258-265. doi: 10.1111/j.1365-2929.2005.02087.x

Magalhaes, E., Salgueira, A. P., Costa, P., and Costa, M. J. (2011). Empathy in senior year and first year medical students: a cross-sectional study. BMC Med. Educ. 11:52. doi: 10.1186/1472-6920-11-52

Magnano, P., Ramaci, T., and Platania, S. (2014). Self-efficacy in learning and scholastic success: implications for vocational guidance. Proc. Soc. Behav. Sci. 116, 1232-1236. doi: 10.1016/j.sbspro.2014.01.374

Mahoney, S., Sladek, R. M., and Neild, T. (2016). A longitudinal study of empathy in pre-clinical and clinical medical students and clinical supervisors. BMC Med. Educ. 16:270. doi: 10.1186/s12909-016-0777-z

Molero Jurado, M. D. M., Perez-Fuentes, M. D. C., Gazquez Linares, J. J., and Barragan Martin, A. B. (2018). Burnout in health professionals according to 
their self-esteem, social support and empathy profile. Front. Psychol. 9:424. doi: 10.3389/fpsyg.2018.00424

Morse, J. M., Anderson, G., Bottorff, J. L., Yonge, O., O’Brien, B., Solberg, S. M., et al. (1992). Exploring empathy: a conceptual fit for nursing practice? Image J. Nurs. Sch. 24, 273-280. doi: 10.1111/j.1547-5069.1992.tb0 0733.x

Öhlén, J., and Segesten, K. (1998). The professional identity of the nurse: concept analysis and development. J. Adv. Nurs. 28, 720-727. doi: 10.1046/j.1365-2648. 1998.00704.X

Pan, Y., Yang, X. H., He, J. P., Gu, Y. H., Zhan, X. L., Gu, H. F., et al. (2015). To be or not to be a doctor, that is the question: a review of serious incidents of violence against doctors in China from 2003-2013. J. Public Health 23, 111-116. doi: 10.1007/s10389-015-0658-7

Patel, R., Huggard, P., and van Toledo, A. (2017). Occupational stress and burnout among surgeons in Fiji. Front. Public Health 5:41. doi: 10.3389/fpubh.2017. 00041

Pollak, K. I., Alexander, S. C., Tulsky, J. A., Lyna, P., Coffman, C. J., Dolor, R. J., et al. (2011). Physician empathy and listening: associations with patient satisfaction and autonomy. J. Am. Board Fam. Med. 24, 665-672. doi: 10.3122/jabfm.2011. 06.110025

Quince, T. A., Parker, R. A., Wood, D. F., and Benson, J. A. (2011). Stability of empathy among undergraduate medical students: a longitudinal study at one UK medical school. BMC Med. Educ. 11:90. doi: 10.1186/1472-6920$11-90$

Rahimi-Madiseh, M., Tavakol, M., Dennick, R., and Nasiri, J. (2010). Empathy in Iranian medical students: a preliminary psychometric analysis and differences by gender and year of medical school. Med. Teach. 32:e00471-8. doi: 10.3109/ 0142159x.2010.509419

Romero, N., Sanchez, A., Vazquez, C., and Valiente, C. (2016). Explicit self-esteem mediates the relationship between implicit self-esteem and memory biases in major depression. Psychiatry Res. 242, 336-344. doi: 10.1016/j.psychres.2016. 06.003

Rosen, I. M., Gimotty, P. A., Shea, J. A., and Bellini, L. M. (2006). Evolution of sleep quantity, sleep deprivation, mood disturbances, empathy, and burnout among interns. Acad. Med. 81, 82-85. doi: 10.1097/00001888-200601000-00020

Rosenberg, M. (1965). Society and the adolescent self-image. Princeton 3, 17801790. doi: 10.1515/9781400876136

Schulte-Ruther, M., Markowitsch, H. J., Shah, N. J., Fink, G. R., and Piefke, M. (2008). Gender differences in brain networks supporting empathy. Neuroimage 42, 393-403. doi: 10.1016/j.neuroimage.2008.04.180

Sherman, J. J., and Cramer, A. (2005). Measurement of changes in empathy during dental school. J. Dent. Educ. 69, 338-345.

Song, Y., and Shi, M. (2017). Associations between empathy and big five personality traits among Chinese undergraduate medical students. PLoS One 12:e0171665. doi: 10.1371 /journal.pone.0171665

Stratton, T. D., Saunders, J. A., and Elam, C. L. (2008). Changes in medical students' emotional intelligence: an exploratory study. Teach. Learn. Med. 20, 279-284. doi: 10.1080/10401330802199625

Thomas, M. R., Dyrbye, L. N., Huntington, J. L., Lawson, K. L., Novotny, P. J., Sloan, J. A., et al. (2007). How do distress and well-being relate to medical student empathy? A multicenter study. J. Gen. Intern. Med. 22, 177-183. doi: 10.1007/s11606-006-0039-36

Toto, R. L., Man, L., Blatt, B., Simmens, S. J., and Greenberg, L. (2015). Do empathy, perspective-taking, sense of power and personality differ across undergraduate education and are they inter-related? Adv. Health Sci. Educ. Theory Pract. 20, 23-31. doi: 10.1007/s10459-014-9502-z

Toussaint, L., and Webb, J. R. (2005). Gender differences in the relationship between empathy and forgiveness. J. Soc. Psychol. 145, 673-685. doi: 10.3200/ socp.145.6.673-86

Veloski, J. J., Fields, S. K., Boex, J. R., and Blank, L. L. (2005). Measuring professionalism: a review of studies with instruments reported in the literature between 1982 and 2002. Acad. Med. 80, 366-370. doi: 10.1097/00001888200504000-00014

Wang, D. Z., Zou, Y., Li, X. W., and Li, Y. M. (2014). Status survey on medical students' professional thinking and the analysis of influencing factors. J. Shanghai Jiaotong Univ. 34, 230-234.

Watson, D., Suls, J., and Haig, J. (2002). Global self-esteem in relation to structural models of personality and affectivity. J. Pers. Soc. Psychol. 83, 185-197. doi: 10.1037/0022-3514.83.1.185

Wen, D., Ma, X., Li, H., Liu, Z., Xian, B., and Liu, Y. (2013). Empathy in Chinese medical students: psychometric characteristics and differences by gender and year of medical education. BMC Med. Educ. 13:130. doi: 10.1186/1472-6920$13-130$

West, C. P., Huschka, M. M., Novotny, P. J., Sloan, J. A., Kolars, J. C., Habermann, T. M., et al. (2006). Association of perceived medical errors with resident distress and empathy: a prospective longitudinal study. JAMA 296, 1071-1078. doi: 10.1001/jama.296.9.1071

Winefield, H. R., and Chur-Hansen, A. (2000). Evaluating the outcome of communication skill teaching for entry-level medical students: does knowledge of empathy increase? Med. Educ. 34, 90-94. doi: 10.1046/j.1365-2923.2000. 00463.x

Xiangkui, Z., and Lumei, T. (2005). The buffering effect of self-seteem on the depressive and anxious reactions to induced failure. Acta Psychol. Sin. 37, 241-245.

Youssef, F. F. (2016). Medical Student stress, burnout and depression in Trinidad and Tobago. Acad. Psychiatry 40, 69-75. doi: 10.1007/s40596-015-0468-9

Yuguero Torres, O., Esquerda Areste, M., Marsal Mora, J. R., and Soler-Gonzalez, J. (2015). Association between sick leave prescribing practices and physician burnout and empathy. PLoS One 10:e0133379. doi: 10.1371/journal.pone. 0133379

Zhao, J., Feng, K., and Wang, Y. (2012). Self-esteem and humor style as mediators of the effects of shyness on loneliness among Chinese college students. Pers. Individ. Diff. 52, 686-690. doi: 10.1016/j.paid.2011.12.024

Zhou, J., Yang, Y., Qiu, X., Yang, X., Pan, H., Ban, B., et al. (2016). Relationship between anxiety and burnout among Chinese physicians: a moderated mediation model. PLoS One 11:e0157013. doi: 10.1371/journal.pone. 0157013

Conflict of Interest Statement: The authors declare that the research was conducted in the absence of any commercial or financial relationships that could be construed as a potential conflict of interest.

Copyright (c) 2019 Huang, Thai, Zhong, Peng, Koran and Zhao. This is an open-access article distributed under the terms of the Creative Commons Attribution License (CC BY). The use, distribution or reproduction in other forums is permitted, provided the original author(s) and the copyright owner(s) are credited and that the original publication in this journal is cited, in accordance with accepted academic practice. No use, distribution or reproduction is permitted which does not comply with these terms. 